\title{
Dermatomyositis: The lesser known aspects.
}

\author{
Anubhav Chauhan ${ }^{1 *}$ Shveta Chauhan ${ }^{2}$ \\ ${ }^{1}$ Department of Ophthalmology, Dr Yashwant Singh Parmar Govt. Medical College, Himachal Pradesh, India \\ ${ }^{2}$ Pine Castle, Near Mist Chamber, Khalini, Shimla 171002, Himachal Pradesh, India
}

\section{Introduction}

Dermatomyositis is an idiopathic inflammatory myopathy with the diagnostic criteria for the disease being typical cutaneous features, progressive proximal symmetrical muscle weakness, elevated muscle enzymes and abnormal findings from muscle biopsy. Other associations being dysphagia, cardiac disturbances, pulmonary symptoms, subcutaneous calcifications, and symptoms like fever, malaise, weight loss, arthralgia and Raynaud's phenomenon [1]. Various ocular complications and oral cavity involvements are present in dermatomyositis but regretfully, very little information is shared among various specialities regarding these aspects.

Ptosis of the eyelids, diplopia and strabismus due to extraocular muscle involvement can be seen. Other manifestations are conjunctival edema, nystagmus, cotton wool spots, optic atrophy, conjunctival pseudopolyposis and lens abnormalities. In addition, vasculitis involving the conjunctival vessels can produce infarction [2]. Conjuctivitis, episcleritis, uveitis, glaucoma and macular oedema are other known complications. Retinopathy associated with dermatomyositis is a rare complication and it completely resolves without lasting long. Profound visual loss in dermatomyositis is caused by macular haemorrhage or macular oedema, which produces central scotomas [3]. Oral manifestations in the form of gingival telangiectases are an important diagnostic marker of juvenile dermatomyositis [4]. Though very little is known about it. Edema without erythema on the tongue and palate [5] lip ulceration [6] hyposalivation with dental caries [7] and oral candidiasis [8] has also been reported. Oral soft tissues like the tongue, mouth floor, salivary glands, buccal mucosa, and muscles of mastication may show evidence of calcium deposits. Anomalies of root formation have been reported previously, along with calcific obliteration of the pulp canals in both primary and permanent teeth. Minimal root resorption has been noted in the primary dentition [9]. Hence, a mandatory Ophthalmic and Oral cavity examination must be carried out in these patients.

Treatment of dermatomyositis is the administration of high-dose glucocorticoids. About $70 \%$ of patients respond initially and move on to the tapering of the glucocorticoids. Other treatment modalities include immunosuppressants like methotrexate, azathioprine, cyclophosphamide and calcineurin inhibitors like ciclosporine $\mathrm{A}$ and tacrolimus. Recently, myocophenolate mofetil has come into use and it seems effective for patients who are refractory to other immunosuppressants, although infection is often a serious side-effect. Based on the assumption that humoral immunity drives inflammation in dermatomyositis, the B cell-depleting monoclonal antibody, rituximab, has been trialed in therapy. Although no randomized studies have yet been carried out, rituximab appeared to be effective in treating dermatomyositis. Use of IV immunoglobulin in treating patients resistant and/ or intolerant to other drugs has also been reported [10].

\section{Source of Support}

None

\section{Conflicts of Interest}

The authors declares that there are no competing interest.

\section{Financial Disclosure}

The authors have no proprietary or commercial interest in any material discussed in this article.

\section{References}

1. Kalyan M, Kanitkar SA, Gaikwad AN. Dermatomyositis: A case report. J Mahatma Gandhi Inst Med Sci 2016;21: 53-5.

2. Dourmishev LA, Dourmishev AL. Ophthalmic Complications of Dermatomyositis. Dermatomyositis Advances in Recognition. Understanding and Management 2009;93-5.

3. Backhouse O, GriYths B, Henderson T. Ophthalmic manifestations of dermatomyositis. Ann Rheum Dis 1998;57: 447-49.

4. GONÇALVES L, BEZERRA JÚNIOR JR, GORDÓN NÚÑEZ MA. Oral manifestations as important symptoms for juvenile dermatomyositis early diagnosis: a case report. Int J Clin Pediatr Dent 2011;21: 77-80.

5. Dourmishev LA, Dourmishev AL. Oral Manifestations of Dermatomyositis. Dermatomyositis: Advances in Recognition, Understanding and Management 2009;61-3.

6. Agbo-Godeau S, Bertrand JC. Lip ulceration in paraneoplastic dermatomyositis. Apropos of a case. Review of the literature. Revue de stomatologie et de chirurgie maxillo-faciale 1993;94: 287.

7. Márton K, Hermann P, Dankó K. Evaluation of oral manifestations and masticatory force in patients with polymyositis and dermatomyositis. J Oral Pathol \& med 2005;34:164-69. 
8. Ferreira DD, Santos KR, Herdy GV. Oral chronic hyperplastic candidiasis associated with juvenile dermatomyositis Revista da Sociedade Brasileira de Medicina Tropical 2012;45: 540.

9. Hamlin C, Shelton JE. Management of oral findings in a child with an advanced case of dermatomyositis: clinical report. Pediatr Dent 1984;6: 46-9.

10. Kohsaka H. Current insights in polymyositis and dermatomyositis. Clinical and Experimental Neuroimmunology 2010;1: 22-32.

\section{*Correspondence to:}

Anubhav Chauhan

Department of Ophthalmology,

Dr Yashwant Singh Parmar Govt. Medical College

India

Tel: +919816991482;

E-mail: chauhan.anubhav2@gmail.com 